\title{
Projeção dos Índices de Desempenho em Instituições Financeiras Brasileiras
}

\author{
Edson Roberto Macohon ${ }^{1}$ \\ Neusa Gonçalves Sala ${ }^{2}$ \\ Nelson $\mathrm{Hein}^{3}$
}

\section{Resumo}

O objetivo deste artigo é analisar a projeção dos índices de desempenho das instituições financeiras brasileiras. A pesquisa é caracterizada como pesquisa descritiva, documental e quantitativa. Foram utilizados dados de índices financeiros disponibilizados no banco de dados Economática, com posições consolidadas em dezembro de cada ano, para os exercícios correspondentes aos anos de 2005 a 2011, para 32 empresas atuantes no mercado de finanças e seguros brasileiro, com ações negociadas na BM\&FBovespa. A técnica estatística utilizada foi Regressão Linear, o software adotado foi o Statgraphics. Verificou-se que a partir dos testes efetuados para os indicadores dos últimos seis anos selecionados do padrão USBank é possível prever com alto grau de confiabilidade o comportamento dos índices para o próximo ano, identifica-se que os índices que possuem maior tendência explicativa são Rentabilidade do Ativo (RentAt), Exigibilidade do Ativo (Exg/At), Margem Bruta (Marg/Bru) e Rentabilidade do Patrimônio Liquido Médio (RentPat(med)), é possível dizer que estes indicadores sofrem menos volatilidade e são mais estáveis frente ao comportamento do mercado. As análises realizadas apontam que os indicadores Lucro por Ação (LPA) e Exigibilidade do Patrimônio Líquido (Exig/PL) podem prever com menor grau de certeza o comportamento dos índices para o próximo ano.

Palavras-chave: Projeção. Índices de desempenho. Instituições financeiras.

\section{Projection of Performance Indexes in Brazilian Financial Institutions}

\begin{abstract}
The aim of this paper is to analyze the projection of the performance indexes of Brazilian financial institutions. The research is characterized as descriptive, documental and quantitative. The financial ratios of data available in the database were used Economática with consolidated positions in December of each year, for the years corresponding to the years 2005 to 2011, 32 companies operating in the Brazilian financial and insurance market, with shares traded on the BM\&FBovespa. The statistical technique used was linear regression, the software used was the Statgraphics. It was found that from the tests conducted for the indicators of the last six years selected from USBank standard is possible to predict with a high degree of reliability the behavior of indices for next year, it is identified that the indexes that have greater explanatory trend are Profitability Assets (RentAt) Assets Chargeability

\footnotetext{
${ }^{1}$ Doutorado em Ciências Contábeis e Administração. Professor da Universidade Estadual do Centro-Oeste UNICENTRO. ermacohon@irati.unicentro.br

2 Doutorado em Ciências Contábeis e Administração. Universidade Regional de Blumenau - FURB. neusalla@via-rs.net

3 Doutorado em Engenharia de Produção. Professor da Universidade Regional de Blumenau - FURB. hein@furb.br
} 
(EXG/at) Gross Margin (Marg/Bru) and Net Average Equity Profitability (RentPat (med)), you can say that these indicators suffer less volatility and are more stable against the market behavior. The analyzes show that the indicators Earnings per share (EPS) and Enforceability of Shareholders' Equity (exif/PL) may provide less certainty the behavior of rates for next year.

Keywords: Projection. Performance Indexes. Financial Institution.

\section{Introdução}

A crescente importância atribuída ao desempenho empresarial tanto na economia brasileira quanto internacionalmente, vem levando diversas instituições financeiras a avaliarem a lucratividade de um investimento e a projetarem índices de desempenho econômicos e financeiros. Este procedimento é visto como um diferencial, ao focalizar os serviços financeiros como recursos para agregação de valores aos produtos postos à disposição dos investidores.

O índice de confiança de serviços (ICS) e o índice de expectativas (IE) nas instituições financeiras são vislumbrados quando há maior transparência das instituições financeiras. A confiança é definida como o resultado de uma relação de conformidade que se estabelece entre o comportamento ideal e o real de uma instituição; por isso, fatos do dia a dia podem interferir na credibilidade das instituições (CAVALLARI, 2012). Neste sentido, o índice de expectativa mede o grau de otimismo do consumidor com relação à evolução da situação econômica e financeira do futuro próximo das instituições.

A projeção de desempenho dos índices econômicos e financeiros das instituições financeiras aumenta a expectativa de confiabilidade dos investidores, no que tange ao retorno/risco associados aos investimentos.

A contabilidade vem se aperfeiçoando no decorrer dos anos com objetivo de apresentar aos seus usuários, ferramentas que sejam capazes de expressar eficientemente a posição patrimonial, econômica e financeira das empresas. A partir do uso de métodos e técnicas que proporcionam aos gestores informações relevantes no processo de tomada de decisões e na avaliação do desempenho empresarial (CARVALHO; SANTOS; RÊGO, 2010).

Segundo os referidos autores as alterações na conjuntura econômica, introduzidas pela globalização, têm levado as empresas a adotarem um processo contínuo de medição de seu desempenho com o fim de atingir um resultado favorável, alinhado aos seus objetivos. Para a mensuração do desempenho empresarial, segundo Macedo e Silva (2004), existem várias 
formas de se proceder a análise das atividades, no entanto devem ser selecionados os itens que melhor representam o comportamento da entidade, e quais os meios que serão utilizados como parâmetros para a apuração de sua eficiência.

De acordo com Vicini e Souza (2005), a estatística mostra-se como uma poderosa ferramenta para a análise e avaliação de dados, em várias áreas do conhecimento. A estatística multivariada desenvolvida a partir do advento dos computadores possibilita a avaliação de dados matemáticos ou estatísticos, sobre produtos ou processos, cada vez mais complexos e abstratos para o senso comum.

Quando um fenômeno depende de muitas variáveis, como o fenômeno contábil, não basta conhecer informações estatísticas isoladas, é necessário, também, conhecer a totalidade dessas informações fornecidas pelo conjunto das variáveis e suas relações, a estatística multivariada. Assim, a capacidade computacional vem viabilizando que o reconhecimento de padrões de imensas tabelas numéricas (ou matrizes), torne possível olhar para os dados e visualizar informações fundamentais para as empresas.

Para Neto (2004) a análise multivariada corresponde a um grande número de métodos e técnicas que utilizam simultaneamente, todas as variáveis na interpretação teórica do conjunto de dados obtidos. Em face da importância dessa temática, este artigo busca responder a seguinte questão: Qual a projeção dos índices de desempenho das instituições financeiras brasileiras? Desta forma, o objetivo deste artigo é analisar a projeção dos índices de desempenho das instituições financeiras brasileiras.

A relevância do tema dá-se por meio das publicações científicas internacionais, as quais destacam-se Aebi; Sabato; Schmid, (2011) sobre a influência de mecanismos de governança corporativa no conselho executivo de um Banco (governança de risco).

Jin Yiqiang; Kanagaretnam; Lobo (2011) examinaram a capacidade de prever falência das variáveis contábeis e de auditoria em bancos durante a crise financeira. Os resultados demonstraram que o serviço de auditoria sério e competente tende a oferecer maior segurança, além disso, mesmo em um setor altamente regulado, como o bancário, a contabilidade desempenha um importante papel de transmitir informações prospectivas aos stakeholders.

O estudo de Dick-Nielsena; Feldhütte; Landoa (2012) investiga a liquidez das ações de empresas durante 2005 a 2009. Contatou-se que a falta de liquidez aumentou dramaticamente com o início da crise subprime. 
O índice de Confiança de Serviços (ICS) caiu 4,8\% em abril ante abril de 2011, a nona taxa negativa consecutiva. $O$ índice de Situação Atual, que mede a percepção sobre o momento atual, recuou $8,3 \%$, enquanto o índice de Expectativas, que mostra a perspectiva para o cenário futuro caiu $1,9 \%(\mathrm{FGV}, 2012)$.

Neste artigo utilizou-se a análise estatística de regressão linear para projetar o comportamento dos índices de desempenho das instituições financeiras brasileiras.

\section{Fundamentação Teórica}

\section{1 Índices de Desempenho Empresarial}

A empresa é uma entidade artificial sem intelecto, nem habilidades para tomada de decisões, tendo seus objetivos determinados por estratégias definidas pela alta administração (ANTONY; GOVINDARAJAN, 2002). Estas estratégias de acordo com Atkinson et al. (2000) estão relacionadas às exigências dos stakeholders.

As estratégias estão relacionadas ao conceito de desempenho, que de acordo com Barney (2002), é o resultado da comparação entre o valor criado pela organização e o valor esperado pelos acionistas. Se o resultado for satisfatório, os recursos continuarão disponíveis, caso contrário, os acionistas podem procurar formas alternativas de retorno (BARNEY, 2002).

Ghalayini e Noble (1996) destacam que a literatura sobre medidas de desempenho teve duas fases principais. A primeira fase iniciou-se ao final de 1880 e atravessou a década de 1980. Nesta fase a ênfase era sobre medidas financeiras, como lucro, retorno sobre o investimento e produtividade. A segunda fase começou no final de 1980, como resultado de mudanças no mercado mundial, da qual revelou que medidas de desempenho tradicionais têm muitas limitações e o desenvolvimento de novos sistemas de medição se fazem necessários para o êxito na avaliação do desempenho.

Cool e Schendel (1987) sugerem um conceito claramente multidimensional, o emprego de múltiplos indicadores para se obter uma avaliação consistente do desempenho. Mehra (1996) utilizou os aspectos de rentabilidade e produtividade seguindo a recomendação de Chakravarthy (1986) para avaliar o desempenho na área financeira.

Critérios objetivos de avaliação de desempenho, tais como retorno sobre investimento (ROI), retorno sobre vendas (ROS), retorno sobre ativos (ROA), crescimento de vendas e 
parcelas de mercado, dominam a literatura. Estes indicadores foram utilizados em diversos estudos de estratégia competitiva, tais como os realizados por Porter (1980), Dess e Davis (1984), Cool e Schendel (1988).

Morozowski Filho e Silveira (1998) referem que os indicadores mais usados para avaliação do desempenho empresarial são o retorno sobre o ativo (ROA - Return on Assets) e o retorno sobre o Patrimônio Líquido (ROE - Return on Equity). Estes indicadores também "são os mais utilizados pelos bancos para medir a sua lucratividade" (ATLANTA FEDERAL RESERVE, 1996, P. 1).

Esses são indicadores, incluindo-se ainda, o LL - Lucro Líquido, o RI - Residual Income - Lucro Residual, são medidas tradicionais que serviram de base para remuneração variável por um longo período de tempo, anteriores ao EVA - Economic Value Added ou Valor Econômico Agregado, cuja origem está na ideia de lucro residual da primeira década do século XX - teoria neoclássica. O EVA inova por representar uma tentativa de “operacionalizar" o conceito de custo de oportunidade (ROCHA; SELIG, 2012).

Novos conceitos na área de gestão normalmente são validados fora do mainstream da organização, o que possibilita que seus aspectos inovadores se destaquem. Mas isso causa ou pode causar problemas, porque é menos provável que o desempenho global da organização seja melhorado por uma iniciativa isolada da sua estratégia.

\subsection{1 Índices Econômicos}

Um indicador econômico é uma ferramenta que permite a obtenção de informações sobre uma dada realidade (MITCHELL, 1996). Um indicador pode ser um dado individual ou um agregado de informações. Para ser um bom indicador deve ser simples de entender; ter quantificação estatística e lógica coerente; e comunicar eficientemente o estado do fenômeno observado (MUELLER et. al., 1997).

Shields et al. (2002) afirmam que um índice revela o estado de um sistema ou fenômeno. Prabhu et al. (1999) argumentam que um índice pode ser construído para analisar dados através da junção de um jogo de elementos com relacionamentos estabelecidos. Portanto, um índice é o valor agregado final de todo um procedimento de cálculo onde utilizam, inclusive, indicadores como variáveis que o compõem.

De acordo com Siche et al. (2007, p. 140) toma-se o termo índice como um valor numérico que representa a correta interpretação da realidade de um sistema simples ou 
complexo (natural, econômico ou social), utilizando em seu cálculo, bases científicas e métodos adequados. O índice pode servir como um instrumento de tomada de decisão e projeção, e é considerado um nível superior da junção de um jogo de indicadores ou variáveis. O termo indicador é um parâmetro selecionado e considerado isoladamente ou em combinação com outros para refletir sobre as condições do sistema em análise. Normalmente um indicador é utilizado como um pré-tratamento aos dados originais.

Dessa forma, um índice é o resultado do encadeamento de variações percentuais ao longo de um intervalo de tempo de algo que se queira medir, por exemplo, a inflação, juros, os custos de produção de determinado produto, entre outros. São muito utilizados porque facilitam o cálculo de variações percentuais acumuladas entre determinados períodos do tempo.

Os índices funcionam como um sinal de alarme para manifestar a situação do sistema avaliado, pois são valores estáticos, isto é, dão uma fotografia do momento atual. A natureza e a economia são sistemas dinâmicos, desta forma, os índices não captam certos fenômenos que ocorrem no sistema, como a mudança tecnológica ou a adaptabilidade dos sistemas sociais (SICHE et. al., 2007).

Os indicadores mais utilizados são aqueles que medem o crescimento da produção; a desvalorização da moeda e aumento de preços; as taxas de conversão de moedas; as taxas básicas de remuneração utilizada no mercado financeiro.

Segundo Gitman (1997), os índices são como um sinalizador de problemas potenciais, devem encontrar os "porquês" dos problemas, isto é, suas causas. Por exemplo, se o índice de liquidez corrente da empresa está declinando, será necessário examinar as mudanças nos componentes do índice para descobrir se as causas são os níveis mais baixos de duplicatas a receber e estoques, ou níveis mais altos de passivo circulante.

Segundo Lourenço e Romero (2012), os indicadores econômicos (IEs) representam essencialmente dados e/ou informações sinalizadoras ou apontadoras do comportamento (individual ou integrado) das diferentes variáveis e fenômenos componentes de um sistema econômico de um país, região ou estado. Por isso, os IEs são fundamentais para uma melhor compreensão da situação presente e o delineamento das tendências de curto prazo da economia, e para subsidiar o processo de tomada de decisões estratégicas dos agentes públicos (governo) e privados (empresas e consumidores). 
Os indicadores econômicos são grandezas de caráter econômico, expressas em valor numérico, cuja principal utilidade consiste na aferição dos níveis de desenvolvimento de países, regiões, empresas, etc. (permitindo, também, como é evidente, efetuar comparações).

$\mathrm{Na}$ análise da situação econômica relativa dos diversos países ou regiões geográficas, é usual comparar indicadores como o Produto Interno Bruto (PIB), o PIB per capita, o saldo das balanças externas, o nível da inflação, a taxa de desemprego, o deficit orçamental, etc. Há indicadores de índole puramente social (por exemplo, número de automóveis, de televisores, de telefones por cada milhar de habitantes) ou demográfica (como a taxa de natalidade, de mortalidade, de mortalidade infantil, a esperança de vida à nascença, etc.).

Os indicadores econômicos procuram avaliar a capacidade da empresa em gerar valor de forma a remunerar adequadamente todos quantos nela participam, nomeadamente os seus acionistas, trabalhadores, entre outros. Alguns exemplos de indicadores econômicos são os diversos indicadores de rentabilidade, eficiência e produtividade (NUNES, 2009). Alguns exemplos de indicadores econômicos: Rentabilidade dos Capitais Próprios; Rentabilidade do Ativo; Rentabilidade das Vendas; Custo dos Capitais Alheios; Produtividade dos Trabalhadores; Eficiência na Gestão de Custos.

\subsection{2 Índices Financeiros}

Na visão de Gitman (1984, p. 219), os índices financeiros podem ser subdivididos em quatro grupos básicos: "Índice de liquidez, atividade, endividamento e lucratividade". Os elementos importantes a curto prazo são liquidez, atividade e lucratividade.

Menon e Ianeski (2007) ressalvam as principais áreas de interesse para cada tipo de índice:

\section{Quadro 1 - Áreas de interesse dos índices de desempenho}

\begin{tabular}{|l|l|}
\hline \multicolumn{1}{|c|}{ Índices } & \multicolumn{1}{c|}{ Áreas de atuação } \\
\hline Liquidez & $\begin{array}{l}\text { A liquidez de uma empresa é medida pela capacidade de satisfazer suas obrigações a curto } \\
\text { prazo, na data de vencimento. As três medidas básicas de liquidez são: o capital circulante } \\
\text { líquido, o índice de liquidez corrente, índice de liquidez seca. }\end{array}$ \\
\hline Atividade & $\begin{array}{l}\text { São usados para medir a rapidez com que várias contas são convertidas em vendas ou caixa. } \\
\text { As medidas de atividade são: giro dos estoques, período médio de cobrança, período médio } \\
\text { de pagamento e giro do ativo total. }\end{array}$ \\
\hline Endividamento & $\begin{array}{l}\text { Indica o volume de dinheiro de terceiros que está sendo usado para gerar lucros. Assim o } \\
\text { grau de endividamento é medido através de duas medidas: Índice de Participação de } \\
\text { Terceiros e Índice Exigível Patrimônio Líquido. }\end{array}$ \\
\hline Lucratividade & $\begin{array}{l}\text { É importante para a empresa, pois é através desta que a mesma se torna lucrativa. As medidas } \\
\text { para esse índice são: margem bruta, margem operacional, margem líquida, retorno capital } \\
\text { investido, retorno sobre o patrimônio líquido, lucro por ação. }\end{array}$ \\
\hline
\end{tabular}


Fonte: Adaptado de Menon e Ianeski (2007).

O diagrama de índices usualmente utilizado é o sistema DuPont. Ele permite determinar a taxa de retorno-lucratividade alcançada por uma empresa sob a forma de lucro/investimento. A vantagem deste sistema é o desdobramento do retorno sobre o patrimônio líquido em três componentes: lucro sobre vendas (margem líquida), eficiência no uso dos ativos (giro do ativo total) e o uso da alavancagem (multiplicador de alavancagem financeira).

A partir do modelo DuPont surgiram outros diagramas onde o original é ajustado de acordo com os interesses de visualização. Entre as alterações está um que decompõe o valor econômico agregado da empresa (MVA mais investimentos totais) (PEDRO; GUERREIRO, 2004).

Os indicadores financeiros procuram avaliar a capacidade da empresa em honrar os seus compromissos financeiros com terceiros dentro dos prazos estipulados e incluem, na perspectiva de longo prazo, os indicadores de estrutura financeira e solvência e, na perspectiva de curto prazo, os indicadores de liquidez (NUNES, 2009).

Muitas são as métricas de desempenho financeiro utilizadas no mercado como o RONA (Return on Net Assets), o CFROI (Cash Flow Return on Investiment) e o EVA (Economic Value Added), entre outros. Conforme Young e O’Byrne (2003, p.20), este último é o indicador responsável pela popularização da medida de valor econômico agregado, largamente utilizado por grandes organizações em todo o mundo.

O EVA e mais que uma simples medida de desempenho, é um sistema completo de gerência financeira e remuneração variável que pode orientar cada decisão tomada por uma empresa (ERBAR apud MÁRIO; JUPETIPE, 2012)

\subsection{Contabilidade Preditiva}

Pode-se entender, a partir da leitura da metodologia contabilométrica, o modelo apresentado por Marion e Silva (1986, p. 39), conforme a Figura 1 a seguir:

\section{Figura 1 - Modelo Contabilométrico}

In Put

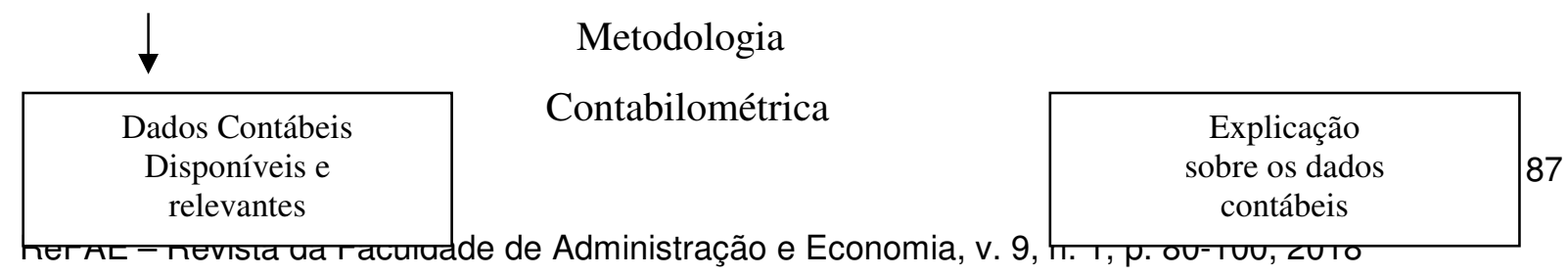




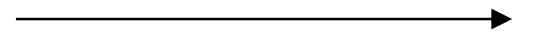

\section{$\uparrow$ \\ Out Put}

Fonte: Marion e Silva (1986, p. 39)

Segundo Silva et al. (2004, p. 6), quanto mais geral o modelo contabilmétrico, maior o número de dados relevantes poderá abranger. Desta forma, uma formação do contador que aprofunde os conhecimentos sobre "Métodos Quantitativos poderia ocupar áreas não bem definidas entre finanças, administração da produção e contabilidade, que levam vantagens de conhecer as origens das informações financeiras - contábeis (o processo) além de possuir o retrato financeiro - econômico da empresa".

Iudícibus (1982) entende que se o contador em vez de usar rudimentarmente o raciocínio puramente aritmético como vem usando, utilizasse modelos contabilmétricos poderia ganhar muito mais em operacionalidade, principalmente "quando deseja antecipar, para prever ou estimular de alguma forma, o que irá ocorrer no futuro de uma empresa”.

Entende-se ser este o princípio da contabilidade preditiva, Silva et al. (2004, p. 6) discorre "não se perca de vista que um modelo contabilmétrico deve ser suficientemente simples [...] o fenômeno contábil que ele representa possa ser entendido claramente e além disso as operações aritméticas, algébricas, analíticas e topológicas ou probabilísticas possam ser realizadas com precisão dentro do contexto das ciências matemáticas".

Para Santos (2004), a contabilometria não significa a simples aplicação de método quantitativo nos problemas contábeis, mas as ciências matemáticas integradas às ciências contábeis na resolução de problemas concretos empresariais (ou de outras entidades) no contexto interdisciplinar. Sabe-se que as ciências matemáticas servem como ferramenta na solução de certos problemas práticos das ciências contábeis, mas entende-se que não é essa a maior contribuição que as ciências matemáticas podem oferecer à contabilidade.

Iudícibus (1982) se dedicou ao estudo dessa temática, definindo em primeira mão a contabilometria como a análise quantitativa de fenômenos contábeis reais baseados no desenvolvimento concomitante da teoria e da observação, relacionados através de métodos apropriados de inferência". Esta definição aponta para a necessidade do acadêmico de ciências contábeis focar suas habilidades, com vistas a desenvolver e aplicar o raciocínio por meio dos métodos quantitativos de modo interdisciplinar com a contabilidade. 


\subsubsection{Planejamento}

No contexto das ciências contábeis e atuariais o estudo de modelos contabilmétricos, oriundos dos métodos quantitativos, são utilizados para a realização de projeções e previsões comportamentais das variáveis, como por exemplo: "Reserva $\mathrm{R}(\mathrm{t})$, Contribuição $\mathrm{C}(\mathrm{t})$, Benefício $\mathrm{B}(\mathrm{t})$, tomando como certo que existirá um fluxo de renda para o infinito, essas variáveis que são responsáveis pelo funcionamento do Sistema Previdenciário, sem as quais esse sistema não se sustentaria" (SILVA et al., 2004, P. 11). Os referidos autores complementam que na visão contábil, esses métodos "dão fidedignidade à gestão de ativos e passivos previdenciários, prezando por uma contabilidade preditiva e pró-ativa, quebrando toda e qualquer retrocessão às tradições de uma contabilidade que só se preocupa com o presente e não é capaz de olhar para o futuro".

Na expressão de Araújo (2001, p. 154), “o objetivo dos sistemas de informação é apresentar os fluxos de informação e estabelecer vinculações com o processo decisório na organização [...] O processo de gestão constitui-se num processo decisório. Decisões requerem informações. Os sistemas de informações devem apoiar as decisões dos gestores em todas as fases do processo de gestão, que requerem informações específicas" (PEREIRA, 1999, P. 61).

A informação contábil deve ser dinâmica e, com isto, atender às rápidas transformações das estratégias organizacionais em função das modificações dos cenários. A contabilidade deve ser preditiva para fornecer informações aos usuários. Cada grupo de tomadores de decisão impõe-lhe limites referentes às informações necessárias às suas decisões, que condicionarão a seleção dos dados de entrada (MISIMANN; FISCH, 1999).

O controle está intrinsecamente relacionado ao planejamento por meio do sistema de feedback que fornece informações sobre o resultado das decisões passadas. Tal sistema é necessário para avaliar a qualidade do processo decisório e seus aprimoramentos (OLIVEIRA, 1999)

\section{Método e Procedimentos da Pesquisa}

O objetivo deste artigo é analisar a projeção dos índices de desempenho das instituições financeiras brasileiras. Desta forma, esta pesquisa é caracterizada como pesquisa descritiva. De acordo com Gil (1999, p. 44) a pesquisa descritiva tem como "objetivo 
primordial a descrição de determinada população ou fenômeno ou o estabelecimento de relações entre variáveis". A pesquisa descritiva observa, analisa e correlaciona fatos ou fenômenos (variáveis) sem manipulá-los (CERVO; BERVIAN, 1996).

Com relação aos procedimentos, trata-se de uma pesquisa documental que de acordo com Raupp e Beuren (2004, p. 89) visa "selecionar, tratar e interpretar a informação bruta, buscando extrair dela algum sentido e introduzir-lhe algum valor podendo, desse modo, contribuir com a comunidade cientifica a fim de que outros possam voltar a desempenhar futuramente o mesmo papel". A pesquisa documental segundo Martins e Teóphilo (2007, p. $55)$ "é característica dos estudos que utilizam documentos como fonte de dados, informações e evidências".

Quanto a abordagem do problema a pesquisa classifica-se como quantitativa. Chizzotti (2003, p. 52) descreve que a pesquisa quantitativa prevê "a mensuração de variáveis preestabelecidas, procurando verificar e explicar sua influência sobre outras variáveis, mediante a análise da frequência de incidências e de correlações estatísticas. $\mathrm{O}$ pesquisador descreve, explica e prediz". O método quantitativo representa "a intenção de garantir a precisão nos resultados, evitar distorções de análise e interpretações, possibilitando, conseqüentemente, uma margem de segurança quanto às inferências" (RICHARDSON, 1999, P. 70).

\subsection{Seleção de Amostra e Estatística Descritiva}

Foram utilizados dados de índices financeiros disponibilizados no banco de dados Economática, com posições consolidadas em dezembro de cada ano, para os exercícios correspondentes aos anos de 2005 a 2011, para 32 empresas atuantes no mercado de finanças e seguros brasileiro, com ações negociadas na BM\&FBovespa.

Os índices selecionados decorrem do padrão USBank os quais expressam aspectos econômicos e financeiros das empresas pertencentes da amostra da pesquisa. Os seguintes índices foram analisados: Rentabilidade do Ativo (RentAt), Exigível pelo Ativo (ExAt), Lucro por Ação (LPA), Exigível pelo Patrimônio Líquido (ExgPL), Margem Bruta (MgrBru) e Rentabilidade do Patrimônio Líquido Médio (RenPLM).

Os índices estão expressos em percentuais correspondentes ao período de 12 meses do exercício fiscal de cada ano, com posições consolidadas e ajustadas. 
Após a coleta dos dados nas demonstrações financeiras este estudo utiliza-se de técnicas estatísticas e de análise multivariada para calcular a Regressão Linear:

a) Verificar o relacionamento de cada índice do ano anterior de projeção (variável dependente) com o respectivo índice do ano subsequente (variável independente);

b) Verificar a possibilidade de antever para dois anos, 2012 e 2013, o comportamento dos índices por meio do desempenho medido pelos respectivos índices no ano de 2011;

c) Identificar os índices de desempenho com maior grau de correlação entre o período realizado (ano anterior) e do período projetado.

A equação de regressão utilizada para o cálculo dos modelos é a seguinte:

$$
\mathrm{y}=\mathrm{a}+\mathrm{b} . \mathrm{X}
$$

Calculou-se média ponderada móvel nos campos que estavam sem informação no banco de dados Economática. O software utilizado para o cálculo das regressões é o Statgraphics. Os pesquisadores utilizaram também o software Excel para calcular as fórmulas de regressão, bem como as médias ponderadas móveis.

Para medir a robustez do modelo foram analisadas as estatísticas $\mathrm{R}, \mathrm{R}$ quadrado, $\mathrm{R}$ quadrado corrigido e o Erro padrão. A estatística R quadrado corrigido é um avaliador mais ajustado da performance do modelo que o R quadrado por compensar a complexidade do modelo. Para comprovar se realmente o problema de multicolinearidade foi eliminado das regressões realizou-se as estatísticas de t e Sig, para medir a significância das variáveis (HAIR ET AL., 1998).

\section{Análise dos Resultados}

\subsection{Análise de Regressão}

Evidencia-se na Tabela 1 os modelos de regressão linear dos índices contemplados pelo estudo para os seis anos, período 2006 a 2011. O objetivo desta validação é evidenciar os níveis de significância do modelo.

Tabela 1 - Resultado das Regressões para o período que antecede 2012.

\begin{tabular}{lrrrrrrrrr}
\hline \multicolumn{1}{c}{ Variáveis } & Coeficientes & Erro Padrão & Estatística t & p-Valor & Estatística-F & p-Valor & R $^{2}$ & $\mathrm{R}^{2}$-Ajustado \\
\hline RentAt & 0,9978 & 1,1275 & 1,7364 & 0,0918 & 7326,0300 & 0,0000 & 99,5516 & 99,5380 \\
\hline Exg/At & 0,9331 & 5,0444 & 2,9642 & 0,0056 & 222,1400 & 0,0000 & 87,0660 & 86,6740 \\
\hline LPAl & 0,8226 & 0,5929 & $-0,3989$ & 0,6926 & 66,9500 & 0,0000 & 67,6609 & 66,6503 \\
\hline Exig / PL & 0,8636 & 238,9999 & 2,8966 & 0,0066 & 96,8000 & 0,0000 & 74,5764 & 73,8060 \\
\hline
\end{tabular}




\begin{tabular}{|c|c|c|c|c|c|c|c|c|}
\hline MrgBru & 0,9429 & 6,8417 & 3,2634 & 0,0026 & 256,2100 & 0,0000 & 88,8970 & 88,5500 \\
\hline RenPat(med) & 0,9964 & 7,2749 & $-0,0994$ & 0,9215 & 4453,4100 & 0,0000 & 99,2866 & 99,2643 \\
\hline \multicolumn{9}{|c|}{ Modelo 2007} \\
\hline Variáveis & Coeficientes & Erro Padrão & Estatística $t$ & p-Valor & Estatística-F & p-Valor & $\mathrm{R}^{2}$ & $\mathrm{R}^{2}$-Ajustado \\
\hline RentAt & 0,9932 & 1,0295 & 6,5809 & 0,0000 & 2387,0000 & 0,0000 & 98,6364 & 98,5950 \\
\hline Exg/At & 0,9695 & 5,5018 & 0,8243 & 0,4157 & 516,4000 & 0,0000 & 93,9935 & 93,8115 \\
\hline LPAI & 0,8028 & 0,5542 & 3,6294 & 0,0010 & 58,0000 & 0,0000 & 64,4428 & 63,3316 \\
\hline Exig / PL & 0,8196 & 269,3370 & 0,3765 & 0,7090 & 67,5200 & 0,0000 & 67,1708 & 66,1760 \\
\hline MrgBru & 0,8983 & 11,6562 & $-0,1451$ & 0,8855 & 133,7700 & 0,0000 & 80,6957 & 80,0924 \\
\hline RenPat(med) & 0,9963 & 8,4087 & $-0,0578$ & 0,9543 & 4346,2700 & 0,0000 & 99,2691 & 99,2463 \\
\hline \multicolumn{9}{|c|}{ Modelo 2008} \\
\hline Variáveis & Coeficientes & Erro Padrão & Estatística t & p-Valor & Estatística-F & p-Valor & $\mathrm{R}^{2}$ & $\mathrm{R}^{2}$-Ajustado \\
\hline RentAt & 0,9718 & 3,4451 & $-1,8090$ & 0,0796 & 559,5800 & 0,0000 & 94,4311 & 94,2623 \\
\hline Exg/At & 0,9139 & 10,7572 & $-0,9454$ & 0,3513 & 167,2600 & 0,0000 & 83,5216 & 83,0222 \\
\hline LPAI & 0,6273 & 1,5178 & $-0,2636$ & 0,7938 & 20,7600 & 0,0001 & 39,3522 & 37,4569 \\
\hline Exig / PL & 0,6369 & 449,6310 & 1,7613 & 0,0874 & 22,5200 & 0,0000 & 40,5649 & 38,7638 \\
\hline MrgBru & 0,8742 & 12,6225 & $-1,2659$ & 0,2147 & 103,7100 & 0,0000 & 76,4200 & 75,6832 \\
\hline RenPat(med) & 0,9901 & 10,7359 & 0,8368 & 0,4089 & 1599,7600 & 0,0000 & 98,0389 & 97,9776 \\
\hline \multicolumn{9}{|c|}{ Modelo 2009} \\
\hline Variáveis & Coeficientes & Erro Padrão & Estatística t & p-Valor & Estatística-F & p-Valor & $\mathrm{R}^{2}$ & $\mathrm{R}^{2}$-Ajustado \\
\hline RentAt & 0,9749 & 2,3389 & 0,3653 & 0,7172 & 632,3800 & 0,0000 & 95,0404 & 94,8901 \\
\hline Exg/At & 0,9661 & 6,1422 & 3,6957 & 0,0008 & 462,6800 & 0,0000 & 93,3425 & 93,1407 \\
\hline LPAI & 0,4781 & 1,7868 & 2,4694 & 0,0191 & 9,4800 & 0,0042 & 22,8602 & 20,4496 \\
\hline Exig / PL & 0,9504 & 218,8380 & $-1,2611$ & 0,2161 & 307,8000 & 0,0000 & 90,3170 & 90,0236 \\
\hline MrgBru & 0,8989 & 11,5579 & 1,7827 & 0,0841 & 134,7400 & 0,0000 & 80,8087 & 80,2090 \\
\hline RenPat(med) & 0,9766 & 6,9322 & 5,4330 & 0,0000 & 660,5100 & 0,0000 & 95,3791 & 95,2347 \\
\hline \multicolumn{9}{|c|}{ Modelo 2010} \\
\hline Variáveis & Coeficientes & Erro Padrão & Estatística t & p-Valor & Estatística-F & p-Valor & $\mathrm{R}^{2}$ & $\mathrm{R}^{2}$-Ajustado \\
\hline RentAt & 0,9648 & 8,8883 & $-2,9622$ & 0,0056 & 444,5100 & 0,0000 & 93,0891 & 92,8797 \\
\hline Exg/At & 0,9284 & 8,3928 & 2,2567 & 0,0308 & 206,0900 & 0,0000 & 86,1977 & 85,7795 \\
\hline LPAI & 0,4433 & 1,8697 & 2,6416 & 0,0127 & 7,8300 & 0,0086 & 19,6512 & 17,1403 \\
\hline Exig / PL & 0,5152 & 860,8630 & 1,6550 & 0,1074 & 11,9200 & 0,0015 & 26,5388 & 24,3127 \\
\hline MrgBru & 0,8847 & 10,6017 & 4,4079 & 0,0001 & 115,2200 & 0,0000 & 78,2635 & 77,5843 \\
\hline RenPat(med) & 0,9722 & 39,7834 & $-6,3442$ & 0,0000 & 550,7400 & 0,0000 & 94,5087 & 94,3371 \\
\hline \multicolumn{9}{|c|}{ Modelo 2011} \\
\hline Variáveis & Coeficientes & Erro Padrão & Estatística t & p-Valor & Estatística-F & p-Valor & $\mathrm{R}^{2}$ & $\mathrm{R}^{2}$-Ajustado \\
\hline RentAt & 0,9772 & 3,1263 & 3,4811 & 0,0014 & 699,4700 & 0,0000 & 95,4947 & 95,3581 \\
\hline Exg/At & 0,9688 & 5,2066 & 2,2100 & 0,0341 & 504,9200 & 0,0000 & 93,8652 & 93,6793 \\
\hline LPAI & 0,7975 & 1,5965 & 0,3327 & 0,7415 & 55,9300 & 0,0000 & 63,6063 & 62,4690 \\
\hline Exig / PL & 0,7435 & 335,0290 & 5,0870 & 0,0000 & 40,8000 & 0,0000 & 55,2838 & 53,9288 \\
\hline MrgBru & 0,8883 & 11,3180 & $-0,8688$ & 0,3914 & 119,7700 & 0,0000 & 78,9159 & 78,2570 \\
\hline RenPat(med) & 0,9902 & 7,4457 & 7,5394 & 0,0000 & 1605,6200 & 0,0000 & 98,0459 & 97,9849 \\
\hline
\end{tabular}

Fonte: Dados da pesquisa.

Verifica-se na Tabela 1 que o índice Rentabilidade do Ativo (RentAt) apresenta Pvalor $<0,05$, indicando que existe relação estatisticamente significativa para 2007, 2010 e 2011. No entanto, o coeficiente de correlação indica que nos seis exercícios existe forte relação entre as variáveis $x$ e $y$. Em todos os períodos analisados o coeficiente de determinação ajustado apresentou significância. Os testes de Estatística F indicam que entre os intervalos de confiança existe relevância entre os efeitos das variáveis independentes e 
variáveis dependentes. O teste $\mathrm{t}$ do intercepto demonstra que os exercícios de 2006, 2007, 2009 e 2011 são positivamente correlacionados com valores superiores a zero.

O índice Exigibilidade do Ativo (Exg/At) apresenta P-valor < 0,05 para 2006, 2009, 2010 e 2011 demonstrando que existe relação estatisticamente significativa nestes períodos. O coeficiente de correlação indica que há forte relação entre as variáveis $x$ e $y$ nos seis exercícios. Dentre os períodos analisados o coeficiente de determinação ajustado apresentou menor significância no exercício de 2008, nos demais períodos a proporção explicativa da variabilidade de $\mathrm{Y}$ foi alto. Os testes de Estatística $\mathrm{F}$ indicam que entre os intervalos de confiança há alto grau de ajustamento entre os resíduos à reta. $\mathrm{O}$ teste $\mathrm{t}$ do intercepto demonstra que somente o exercício de 2008 não é positivamente correlacionado.

Nota-se que o índice Lucro por Ação (LPA) apresenta P-valor < 0,05 para 2007, 2009 e 2010 demonstrando que existe relação estatisticamente significativa nestes períodos. Verifica-se que o coeficiente de correlação existe fraca relação entre as variáveis $x$ e $y$ e apresenta queda constante exceto em 2011. Em todos os períodos analisados o $\mathrm{R}^{2}$ ajustado apresentou pouca significância, demonstrando que o poder explicativo do modelo para este índice é baixo. Os testes de Estatística $\mathrm{F}$ indicam que entre os intervalos de confiança existe baixa relevância entre os efeitos das variáveis. O teste $t$ do intercepto demonstra que os exercícios de 2007, 2009, 2010 e 2011 são positivamente correlacionados com valores superiores a zero.

O índice Exigibilidade do Patrimônio Líquido (Exig/PL) apresenta P-valor < 0,05 para 2006 e 2011 demonstrando que existe relação estatisticamente significativa nestes períodos. O coeficiente de correlação apresenta em 2006 e 2009 forte relação entre as variáveis $x$ e $y$, indicando que nestes períodos há alta proporção da variabilidade de Y ser explicada pela variável independente, nos demais exercícios apresenta alta variação com baixa relação entre as variáveis. Nos exercícios analisados o coeficiente de determinação ajustado apresentou alta significância em 2009. Os testes de Estatística F indicam que entre os intervalos de confiança existe baixa relevância entre os efeitos das variáveis. O teste t do intercepto demonstra que, exceto no ano de 2009, os períodos de análise são positivamente correlacionados com valores superiores a zero.

O índice Margem Bruta (Marg/Bru) apresenta P-valor < 0,05 para 2006 e 2010 demonstrando que existe relação estatisticamente significativa nestes períodos. O coeficiente de correlação indica que nos seis exercícios existe forte relação entre as variáveis $x$ e $y$. $\mathrm{O}$ 
coeficiente de determinação ajustado apresentou significância apenas em 2006. Os testes de Estatística $\mathrm{F}$ indicam que entre os intervalos de confiança existe relevância no ajustamento dos resíduos à reta. O teste $\mathrm{t}$ do intercepto demonstra que os exercícios de 2006, 2009 e 2010 são positivamente correlacionados com valores superiores a zero.

O índice Rentabilidade do Patrimônio Liquido Médio (RentPat(med)) apresenta Pvalor < 0,05 para 2009, 2010 e 2011 demonstrando que existe relação estatisticamente significativa nestes períodos. Nota-se que o coeficiente de correlação indica existência de forte relação entre as variáveis $x$ e $y$ para todos os exercícios. Em todos os períodos analisados o coeficiente de determinação ajustado apresentou significância. Os testes de Estatística F indicam que entre os intervalos de confiança existe relevância entre os efeitos das variáveis indicando que há um alto grau de ajustamento dos resíduos. O teste t do intercepto demonstra que os exercícios de 2008, 2009 e 2011 são positivamente correlacionados com valores superiores a zero.

Tabela 2 - Resultado das Regressões para o período de 2012.

\begin{tabular}{lcccccccc}
\hline \multicolumn{1}{c}{ Variáveis } & Coeficientes & $\begin{array}{c}\text { Erro } \\
\text { Padrão }\end{array}$ & $\begin{array}{c}\text { Estatística } \\
\mathrm{t}\end{array}$ & $\begin{array}{c}\mathrm{p}- \\
\text { Valor }\end{array}$ & $\begin{array}{c}\text { Estatística- } \\
\mathrm{F}\end{array}$ & $\begin{array}{c}\mathrm{p}- \\
\text { Valor }\end{array}$ & $\mathrm{R}^{2}$ & $\begin{array}{c}\mathrm{R}^{2}- \\
\text { Ajustado }\end{array}$ \\
\hline RentAt & 0,9772 & 3,05507 & 0,4365 & 0,6653 & 699,4700 & 0,0000 & 95,4947 & 95,3581 \\
\hline Exg/At & 0,9688 & 5,0444 & 1,4211 & 0,1647 & 504,9200 & 0,0000 & 93,8652 & 93,6793 \\
\hline LPAl & 0,7975 & 1,59646 & 2,7075 & 0,0108 & 55,9300 & 0,0000 & 63,6063 & 62,4690 \\
\hline Exig / PL & 0,7435 & 249,104 & 4,2788 & 0,0002 & 40,8000 & 0,0000 & 55,2838 & 53,9288 \\
\hline MrgBru & 0,8883 & 10,0543 & 2,5754 & 0,0148 & 119,7700 & 0,0000 & 78,9159 & 78,2570 \\
\hline RenPat(med) & 0,9902 & 7,37256 & 0,3512 & 0,7277 & 1605,6200 & 0,0000 & 98,0459 & 97,9849 \\
\hline
\end{tabular}

Fonte: Dados da pesquisa.

Verifica-se na Tabela 2 que os índices (RentAt), (Exg/At) e (RenPat(med)) apresenta $\mathrm{P}$-valor $>0,05$, indicando que pode não existir relação estatisticamente significativa para $\mathrm{o}$ período. Os indicadores (LPA), (Exig / PL) e (MrgBru) apresentam P-Valor < 0,05, indicando que existe relação estatisticamente significativa. No entanto, o coeficiente de correlação indica que existe forte relação entre as variáveis $x$ e $y$ para os indicadores (RentAt), (Exg/At), (MrgBru) e (RenPat(med)).

O coeficiente de determinação ajustado apresentou significância para os indicadores (RentAt), (Exg/At) e (RenPat(med)). Os testes de Estatística F indicam que entre os intervalos de confiança existe relevância entre os efeitos das variáveis independentes e variáveis dependentes para os indicadores (RentAt), (Exg/At), (MrgBru) e (RenPat(med)). O teste t do intercepto demonstra que todos os indicadores são positivamente correlacionados com valores superiores a zero. 


\section{Conclusões}

O objetivo do presente estudo é analisar a projeção dos índices de desempenho das instituições financeiras brasileiras. A projeção do desempenho de empresas por meio da utilização de indicadores pode contribuir tanto para a instituição maximizar seu valor quanto para o acionista maximizar seus ganhos.

Os índices selecionados decorrem do padrão USBank os quais expressam aspectos econômicos e financeiros das empresas pertencentes da amostra da pesquisa. Os seguintes índices foram analisados: Rentabilidade do Ativo (RentAt), Exigível pelo Ativo (ExAt), Lucro por Ação (LPA), Exigível pelo Patrimônio Líquido (ExgPL), Margem Bruta (MgrBru) e Rentabilidade do Patrimônio Líquido Médio (RenPLM).

Os pesquisadores consultaram pesquisas acerca da utilização de índices de desempenho para prever situações futuras das empresas. Há duas vertentes de estudos, uma utiliza modelos de previsão de falência e outra que utiliza índices de desempenho para prever valor de mercado futuro.

Para a realização deste estudo utilizou-se a base de dados do software Economática. A técnica estatística utilizada é a análise multivariada de regressão linear. Para medir a robustez do modelo foram analisadas as estatísticas $\mathrm{R}, \mathrm{R}$ quadrado, $\mathrm{R}$ quadrado corrigido e o Erro padrão. A estatística $\mathrm{R}$ quadrado corrigido é um avaliador mais ajustado da performance do modelo que o R quadrado por compensar a complexidade do modelo.

Verifica-se que a partir dos testes efetuados para os indicadores dos últimos seis anos selecionados do padrão USBank é possível prever com alto grau de confiabilidade o comportamento dos índices para o próximo ano, identifica-se que os índices que possuem maior tendência explicativa são Rentabilidade do Ativo (RentAt), Exigibilidade do Ativo (Exg/At), Margem Bruta (Marg/Bru) e Rentabilidade do Patrimônio Liquido Médio (RentPat(med)), é possível dizer que estes indicadores sofrem menos volatilidade e são mais estáveis frente ao comportamento do mercado.

As análises realizadas apontam que os indicadores Lucro por Ação (LPA) e Exigibilidade do Patrimônio Líquido (Exig/PL) podem prever com menor grau de certeza o comportamento dos índices para o próximo ano. No entanto, a Regressão Linear não conseguiu obter correlação significativa para prever o comportamento dos índices para o ano de 2013. 


\section{Referências}

ANTHONY, R. N.; GOVINDARAJAN, V. Sistemas de controle gerencial. São Paulo: Atlas, 2002.

ARAÚJO, L. C. G. Organização, sistemas e métodos: e as modernas ferramentas de gestão organizacional. São Paulo: Atlas, 2001.

ATKINSON, A. A.; BANKER, R. D.; KAPLAN, R. S. et al. Contabilidade gerencial. São Paulo: Atlas, 2000.

ATLANTA FEDERAL RESERVE. Why banks don't make every loan you think they should make. Partners, v. 6, n. 4, 1996.

BARNEY, J. B. Gaining and sustaining competitive advantage. New Jersey: Education Inc., 2002.

CALDAS, V. Porque lucrar não é mais o importante. Revista Contábil \& Empresarial FiscoLegis, maio 2012. Disponível em: <http://www.netlegis.com.br/...=515>. Acesso em: 7 maio 2012.

CALIL, C. F. E. Posicionamento social e desempenho financeiro: uma análise na indústria bancária brasileira a partir de uma tipologia proposta. Dissertação (Mestrado em Administração). PUC-RJ, 2006.

CARVALHO, J.R.M; SANTOS, W. C; RÊGO,T.F. Uma análise dos fatores de desempenho financeiro: o caso das Lojas Americanas S.A. Qualit@s Revista Eletrônica ISSN 16774280 Vol.9. No 12010

CARNEIRO, J.; SILVA, J. F. Medidas contábeis-financeiras como indicadores de desempenho organizacional. $e$ Gesta - Revista Eletrônica de Gestão de Negócios - ISSN 1809-0079, v. 6, n. 3, p. 31-68, jul./set. 2010.

CAVALLARI, M. Índice de Confiança Social, novo produto do IBOPE Inteligência, mede credibilidade das instituições brasileiras. Edição 14. Ano 4.

CERVO, A. L.; BERVIAN, P. A. Metodologia científica. 4. ed. São Paulo: Makron, 1996.

CHAKRAVARTHY, B. S. Measuring strategic performance. Strategic Management Journal, n. 7, p. 437-458, 1986.

CHIZZOTTI, Antônio. A pesquisa em ciências humanas e sociais. 6. ed. São Paulo: Cortez, 2003. 
COOL, K.; SCHENDEL, D. Strategic group formation and performance: the case of the U.S. pharmaceutical industry, 1963-1982. Management Science, v. 33, n. 9, p.1102-1124, 1987.

- Performance differences among strategic group members. Strategic Management Journal, n. 9, p. 207-233, 1988.

COPELAND, T.; KOLLER, T.; MURRIN, J. Valuation: measuring and managing the value of companies. 2nd ed., New York: John Wiley \& Son, Inc. 1996.

DEARDEN, J. The case against ROI control. Harvard Business Review, v. 47, n. 3, p.124$135,1969$.

DESS, G. G.; DAVIS, P. S. Porter's generic strategies as determinants of strategic group membership and organizational performance. Academy of Management Journal, n. 27, p. 467-488, 1984.

GHALAYINI, A. M.; NOBLE, J. S. The changing basis of performance measurement. International journal of operations and production management, v. 16, n. 8, p.63-80, 1996.

GIL, Antônio Carlos. Métodos e técnicas de pesquisa social. 5. ed. São Paulo: Atlas, 1999.

GITMAN, L. Princípios de administração financeira. 7.ed. Sao Paulo: Harbra, 1997. 3.ed. São Paulo: Harper e Row - Harbra, 1994.

HAIR, J. et al. Multivariate data analysis. New Jersey. Prentice Hall. 1998.

HAMBRICK, D. High profit strategies in mature capital goods industries: a contingency approach. Academy of Management Journal, v. 26, p. 687-707, 1983.

HARVEY, T. W.A Framework for understanding the financial performance of the firm using the resource-based view: an empirical investigation. Tese (Doutorado em Administração, Cleveland State University-USA). Cleveland, USA, 2004.

INDICADORES econômicos. Infopédia [Em linha]. Porto: Porto Editora, 2003-2012. Disponível em: <http://www.infopedia.pt/\$indicadores-economicos>. Acesso em: 7 maio 2012.

IUDÍCIBUS, Sérgio de. Existirá a contabilometria. Revista Brasileira de Contabilidade, 1982.

LOURENÇO, G. M.; ROMERO, M. Indicadores econômicos. Disponível em: <http://www.fae.edu/publicacoes/pdf/economia/3.pdf>. Acesso em: 7 maio 2012. 
MACEDO, M. A. S.; SILVA, F. F. Análise de desempenho organizacional: utilizando indicadores financeiros e não financeiros na avaliação de performance empresarial. Anais eletrônicos do XXVIII ENANPAD, Curitiba, 2004.

MARIO, P. C.; JUPETIPE, C. K. N. Estudo de modelos de indicadores financeiros e econômicos na análise de eventos de default. Disponível em: <http://www.congressousp. fipecafi.org/artigos102010/522.pdf>. Acesso em: 6 maio 2012.

MARION, J. C. Preparando-se para a profissão do futuro. Revista Pensar Contábil. Conselho Regional de Contabilidade do Estado do Rio de Janeiro, a. 1, n. 2., nov. 1998.

MARION, J. C.; SILVA,L. B. Contabilometria, novo campo de estudo para a contabilidade. Revista Brasileira de Contabilidade, n. 59,1996.

MARTINS, Gilberto de Andrade; THEÓPHILO, Carlos Renato. Investigação Científica para Ciências Sociais Aplicadas. São Paulo: Atlas, 2007.

MATARAZZO, D. C. Análise financeira de balanços: abordagem básica e gerencial. 6.ed. São Paulo: Atlas S/A, 1998.

MEHRA, A. Resource and market based determinants of performance in the U.S. banking industry. Strategic Management Journal, v. 17, p. 307-322, 1996.

MENON, R. A.; IANESKO, J. A. A utilização de análise através de índices para uma boa administração financeira. Revista Eletrônica Lato Sensu, ISSN 1980-6116, a. 2, n. 1, jul. 2007.

MISIMANN, C. P.; FISCH, S. Controladoria: seu papel na administração de empresas. São Paulo: Atlas, 1999.

MITCHELL, G. Problems and fundamentals of sustainable development indicators. Sustainable Development, v. 4, n. 1, p. 1-11, 1996.

MOROZOWSKI FILHO, M.; SILVEIRA, F. S. V. Planejamento econômico-financeiro de empresas de energia elétrica: uma abordagem adequada ao ambiente competitivo - VI Simpósio de Especialistas em Planejamento da Operação e Expansão Elétrica. Salvador, 1998.

MUELLER, C.; TORRES, M.; MORAIS, M. Referencial básico para a construção de um sistema de indicadores urbanos. Brasília: Instituto de Pesquisa Econômica Aplicada (IPEA), 1997.

NETO, M. M. J. Estatística multivariada. Revista de Filosofia e Ensino, 9 maio 2004. 
NEVES, I. J.; MENDES, F.;CUNHA, M. A. Eficiência operacional: uma análise exploratória dos 50 maiores bancos brasileiros pelo BACEN. $7^{\circ}$ Congresso USP Controladoria e Contabilidade, 2007.

NUNES, P. Conceito de indicadores econômicos e financeiros. (24 abr. 2009). Disponível em: <http://www.knoow.net/cienceconempr/gestao/indicadores_economicos_financeiros. htm>. Acesso em: 5 maio 2012.

OLIVEIRA, A. B. S.. Planejamento, planejamento de lucro. In: CATELLI, A. (coord.) Controladoria: uma abordagem da gestão econômica GECON. São Paulo: Atlas, 1999.

FGV - FUNDAÇÃO GETULIO VARGAS. Agência Estado, 3 de maio de 2012. Disponível em: <>. Acesso em: 5 maio 2012.

PAJARES, F. M. R.; ZILVER, S.; XAVIER, D. L. J. Análise da vantagem competitiva de bancos através do modelo de visão baseada em recursos utilizando indicadores contábeis: estudo comparativo Brasil x Estados Unidos. Congresso USP, out. 2010. Disponível em: <http://www.congressousp.fipecafi.org/artigos102010/362.pdf>. Acesso em: 6 maio 2012.

PEDRO, L. M.; GUERREIRO, R. Aplicação de árvores de decisão na análise financeira. Disponível em: < http://www.congressousp.fipecafi.org/artigos12004/424.pdf>. Acesso em: 6 maio 2012.

PEREIRA, C. A. Ambiente, empresa, gestão e eficácia. In: CATELLI, A. (coord.) Controladoria: uma abordagem da gestão econômica GECON. São Paulo: Atlas, 1999.

PORTER, M. E. Estratégia competitiva: técnicas para análise de indústrias e da concorrência. Rio de Janeiro: Campus, 1980.

PRABHU, R., COLFER, C. J. P., DUDLEY, R. G. Guidelines for developing, testing and selecting criteria and indicators for sustainable forest management. Toolbox Series, n. 1. Indonesia: CIFOR, 1999.

RAPPAPORT, A. Information for decision making. Illinois: Prentice Hall, Inc. 1982.

RAUPP, Fabiano Maury; BEUREN, Ilse Maria.Metodologia da pesquisa aplicável às ciências sociais. In: BEUREN, Ilse Maria (Org.). Como elaborar trabalhos monográficos em contabilidade: teoria e prática. 2. ed. São Paulo: Atlas, 2004, p. 76-97.

REECE, J.; COOL, W. Measuring investment center performance (criticism on ROI). Harvard Business Review, v. 56, n. 3, p. 28-46, 1978. 
ROCHA, J. S.; SELIG, P. M. O uso de indicadores de desempenho como base para remuneração variável nas empresas e suas influencias nos custos. Disponível em: <http://www.contabeis.ufba.br/materialprofessores/...>. Acesso em: 7 maio 2012.

SHIELDS, D.; SOLAR, S.; MARTIN, W. The role of values and objectives in communicating indicators of sustainability. Ecological Indicator, v. 2, n. 1-2, p. 149-160, nov. 2002.

SICHE, R. et al. Índices versus indicadores: precisões conceituais na discussão da sustentabilidade de países. Ambiente \& Sociedade, Campinas, v. X, n. 2, p. 137-148, jul./dez. 2007.

SILVA, M. F. N.; MONTEIRO, G. B.; SILVA, M. L.; RIBEIRO, J. C. Importância do teorema fundamental do cálculo na contabilidade. Disponível em: <http://www. congressousp.fipecafi.org/artigos12004/389.pdf>. Aceso em: 7 maio 2012.

SOUZA, A. C. R. A orientação para o mercado, o relacionamento com os clientes e o desempenho das empresas: um levantamento junto a empresas que atuam na região nordeste do Brasil. Disponível em: <https://www.gruporota.com.br/>. Acesso em: 7 maio 2012.

STEVENSON, W. J. Estatística aplicada à administração. São Paulo: Harper \& Row do Brasil, 1981.

VICINI, L.; SOUZA, A. M. Análise multivariada da teoria à prática. Monografia, 215 p. (Especialização - Universidade Federal de Santa Maria). Santa Maria: UFSM/CCNE, 2005). 